CORRECTION

\title{
Correction to: The stepwise process of integrating a genetic counsellor into primary care
}

\author{
Caitlin Slomp, Emily Morris, GenCOUNSEL Study, Morgan Price, Alison M. Elliott (D) and Jehannine Austin (D)
}

(c) The Author(s), under exclusive licence to European Society of Human Genetics 2022

European Journal of Human Genetics (2022) 30:865; https://doi.org/10.1038/s41431-022-01063-4

Erratum to: European Journal of Human Genetics https://doi.org/ 10.1038/s41431-022-01040-x, published online 31 January 2022
In the original publication of the article, Table 2 was incorrect. The correct Table 2 appears as below.

Table 2. Needs, barriers and facilitators of participants' progression between stages of collaboration.

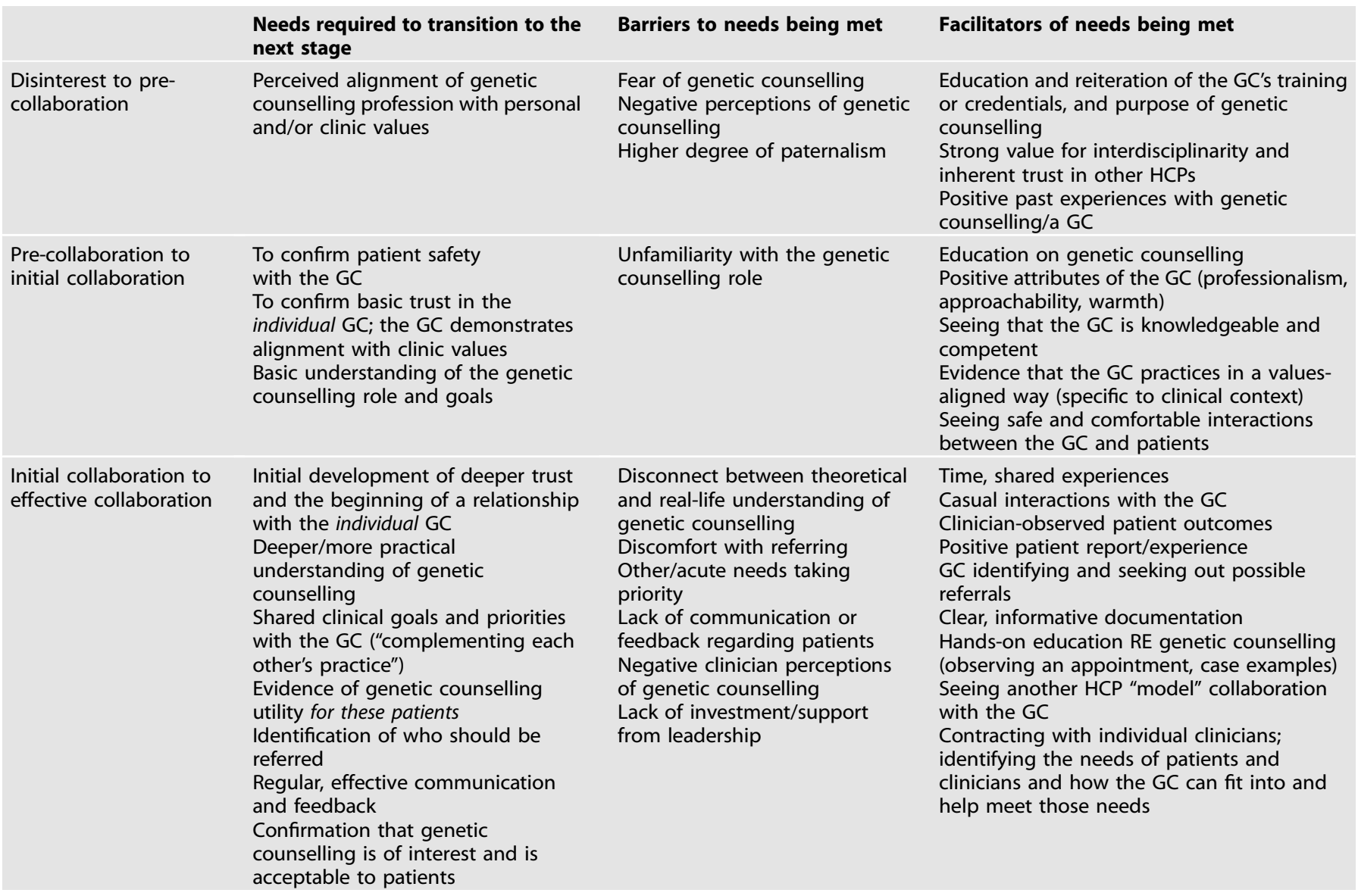

GC genetic counsellor, HCP healthcare professional. 